\title{
Assessment of the prognostic value of two common variants of BRCA1 and BRCA2 genes in ovarian cancer patients treated with cisplatin and paclitaxel: a Gynecologic Oncology Group study
}

\section{Chunqiao Q. Tian ${ }^{1+}$, Kathleen M. Darcy ${ }^{1+}$, Thomas C. Krivak ${ }^{2+}$, Julie A. DeLoia ${ }^{3}$, Deborah Armstrong ${ }^{4}$, Warren Davis ${ }^{5}$, Hua Zhao ${ }^{5}$, Kirsten Moysich ${ }^{5}$ and Christine B. Ambrosone ${ }^{5 *}$}

${ }^{1}$ Gynecologic Oncology Group Statistical and Data Center, Buffalom, NY, USA

${ }^{2}$ Magee Womens Hospital, University of Pittsburgh, Pittsburgh, PA, USA

${ }^{3}$ Georgetown University, Washington, DC, USA

4 John Hopkins Kimmel Cancer Center, Baltimore, MD, USA

${ }^{5}$ Department of Cancer Prevention and Control, Roswell Park Cancer Institute, Buffalo, NY, USA

\section{Edited by:}

Angeles Alvarez Secord, Duke University Medical Center, USA

\section{Reviewed by:}

Xavier Matias-Guiu, Institut de

Recerca Biomedica de Lleida, Spain

Angeles Alvarez Secord, Duke

University Medical Center, USA

\section{*Correspondence:}

Christine B. Ambrosone, Department of Cancer Prevention and Control,

Roswell Park Cancer Institute, Elm

and Carlton Streets, Buffalo, NY

14263, USA

e-mail: christine.ambrosone@

roswellpark.org

${ }^{\dagger}$ Present address:

Chunqiao Q. Tian, Precision

Therapeutics Inc., Pittsburgh, PA

15213, USA; Gynecologic Cancer

Center of Excellence (GYN-COE), The

Women's Health Integrated Research Center (WHIRC), Inova Health

System, Annandale, VA 22003, USA;

Kathleen M. Darcy, Gynecologic

Cancer Center of Excellence

(GYN-COE), The Women's Health

Integrated Research Center (WHIRC)

Inova Health System, Annandale, VA

22003, USA; State University of New

York, Buffalo, NY 14214, USA;

Thomas C. Krivak, Western

Pennsylvania Hospital, Pittsburgh, PA 15224, USA

All authors meet the three criteria for authorship, and each certifies that the manuscript represents valid work and has not been previously published nor is under consideration for publication elsewhere.
Purpose: BRCA1/BRCA2 germline mutations appear to enhance the platinum-sensitivity, but little is known about the prognostic relevance of polymorphisms in BRCA1/BRCA2 in epithelial ovarian cancer (EOC). This study evaluated whether common variants of BRCA1/BRCA2 are associated with progression-free survival (PFS) and overall survival (OS) in patients with advanced stage sporadic EOC.

Experimental Design: The allelic frequency of BRCA1 (2612C > T, P871 L-rs799917) and BRCA2 (114A > C, N372H-rs144848) were determined in normal blood DNA from women in Gynecologic Oncology Group protocol \#172 phase III trial with optimally resected stage III EOC treated with intraperitoneal or intravenous cisplatin and paclitaxel $(C+P)$. Associations between polymorphisms and PFS or OS were assessed.

Results: Two hundred and thirty-two women were included for analyses. African Americans (AA) had different distributions for the two polymorphisms from Caucasians and others. For non-AA patients, the genotype for BRCA1 P871L was distributed as $38 \%$ for CC, $49 \%$ for CT, and $13 \%$ for TT. Median PFS was estimated to be 31, 21, and 21 months, respectively. After adjusting for cell type, residual disease, and chemotherapy regimen, CT/TT genotypes were associated with a 1.40-fold increased risk of disease progression [95\% confidence interval $(\mathrm{Cl})=1.00-1.95, p=0.049]$. After removing seven patients with known BRCA1 germline mutations, the hazard ratio $(\mathrm{HR})$ was $1.36(95 \% \mathrm{Cl}=0.97-1.91$, $p=0.073)$. The association between BRCA $1 \mathrm{P} 871 \mathrm{~L}$ and $\mathrm{OS}$ was not significant $(\mathrm{HR}=1.25$, $95 \% \mathrm{Cl}=0.88-1.76, p=0.212$ ). Genotype distribution of BRCA2 N372H among non-AA patients was 50,44 , and $6 \%$ for $A A, A C$, and $C C$, respectively and there is no evidence that this BRCA2 polymorphism was related to PFS or OS.

Conclusion: Polymorphisms in BRCA1 P871L or in BRCA2 N372H were not associated with either PFS or OS in women with optimally resected, stage III EOC treated with cisplatin and paclitaxel.

Keywords: BRCA, polymorphism, ovarian cancer, chemotherapy, prognosis

\section{INTRODUCTION}

The standard treatment for advanced epithelial ovarian cancer (EOC) begins with cytoreductive surgery followed by chemotherapy consisting of platinum and taxane (1-3). Although tumor response rate to this regimen is as high as $70-80 \%$, the majority of patients relapse within $2-3$ years $(3,4)$. Identification of biomarkers that predict resistance to platinum/taxane-based chemotherapy may allow alternative therapeutic options to be considered for this high-risk group (5). 
Most ovarian cancers are due to sporadic events and $8-10 \%$ are attributable primarily to germline mutations in breast cancer 1 (BRCA1) or BRCA2 genes (6). BRCA1 and BRCA2 are considered tumor suppressor genes, and loss-of-function mutations confer a significantly increased risk of developing breast and ovarian cancer (6). BRCA-associated ovarian cancer patients appear to display a better response to platinum agents as compared to sporadic patients (7-11), likely due to a BRCA-deficient tumor having suboptimal DNA repair and enhanced sensitivity to DNA-damaging drugs (12-14). In sporadic EOC, the inactivation of BRCA through various mechanisms is common and studies in this setting have demonstrated that low levels of BRCA1 mRNA or protein predict improved outcome following platinum-based chemotherapy (15-18). Associations between BRCA1 and treatment outcome have been reported in several solid tumors including lung and colorectal cancers (19-21). Taken together, BRCA1 and BRCA2 appear to play critical roles in development of ovarian cancer and modulation of chemotherapy responsiveness.

A number of polymorphisms have been identified in the BRCA1 gene and P871L (rs799917) is one of the most common variants with a minor allele (T) frequency of $32 \%$ among Caucasian cancer patients $(22,23)$. In the BRCA2 gene, N372H (rs144848) which results in an amino acid change is the most common polymorphism with a minor allele (C) frequency of $27 \%$ among Caucasian cancer patients (22). It is unclear if these common variants in BRCA1 or BRCA2 genes impact therapeutic efficacy and clinical outcome. The prognostic value of these two most common variants in the BRCA1 and BRCA2 genes was examined in normal DNA from women who participated in Gynecologic Oncology Group (GOG) protocol \#172, a phase III trial where patients with stage III EOC were treated with cisplatin + paclitaxel $(\mathrm{C}+\mathrm{P})$.

\section{MATERIALS AND METHODS STUDY POPULATION}

Patients in this study participated in a randomized phase III trial, GOG\#172, and had normal DNA available for genotyping. Details regarding eligibility criteria, treatment, and end points, and the survival advantage for women randomized to intraperitoneal $\mathrm{C}+\mathrm{P}$ compared with intravenous $\mathrm{C}+\mathrm{P}$ for GOG\#172 have been reported elsewhere (28). Women on this study provided written informed consent to participate in GOG\#172 and provide a blood specimen for research consistent with all federal, state, and local requirements.

\section{GENOTYPING}

Genomic DNA was extracted from white blood cells recovered from whole blood as described previously (29). BRCA1 P871L (rs799917) and BRCA2 N372H (rs144848) polymorphisms were genotyped using a MALDI-TOF iPLEXTMGOLD assay (Sequenom, San Diego, CA, USA).

\section{STATISTICAL ANALYSIS}

The genotype data were tested for Hardy-Weinberg equilibrium (HWE) using exact permutation test. Associations between polymorphisms and clinical characteristics were assessed using Wilcoxon rank-sum for continuous variables and using Pearson$\chi^{2}$ or Fisher exact test for categorical variables. Kaplan-Meier procedure was used to estimate progression-free survival (PFS) and overall survival (OS) by genotype. Hazard ratios were estimated using a Cox regression model adjusted for prognostic factors including cell type (clear cell/mucinous vs. other histologic subtypes), residual disease status (gross vs. no gross), and treatment regimen (intraperitoneal vs. intravenous). These variables were selected for adjustment based on previous GOG studies (28-30). Previous studies demonstrated that the distributions of polymorphisms in BRCA1 and BRCA2 varied by race (22), analyses of PFS/OS were performed without African American (AA) women (data shown) and with AA women (data not shown). As some women in GOG\#172 had a known germline mutation in the BRCA 1 gene, PFS/OS analyses were performed with and without these patients.

\section{RESULTS}

Patient characteristics for the 232 women in this study are shown in Table 1 and are representative of that observed in the entire GOG\#172 protocol (28). Approximately 55\% of the women had intravenous (IV) $\mathrm{C}+\mathrm{P}$, with the remainder receiving IP therapy. At the time of analysis, 148 patients had died, 55 women were alive with no evidence of disease, and 29 were alive with documented recurrence/disease progression. The median follow-up period for those still alive was 87 months. Overall, the median PFS of this population was 21.8 months and the median OS was 57.8 months.

\section{BRCA1 P871L POLYMORPHISM ( $N=232$ )}

The BRCA1 P871L polymorphism was associated with race $(p<0.001)$ but not with other clinical variables (Table 2$)$. In particular, there was no difference in genotype distribution between HGS and non-HGS tumors $(p=0.700)$. All seven AA women exhibited the TT genotype. Among non-AA patients, the genotype for P871L in BRCA1 was distributed as 38\% for CC, $49 \%$ for CT, and $13 \%$ for TT, consistent with HWE $(p=0.569)$. Median PFS was 31,21 , and 21 months, respectively (log-rank test for CC vs. CT/TT: $p=0.109$, Figure 1). Median OS was 70, 55, and 59 months for CC, CT, and TT genotypes, respectively (log-rank test for CC vs. CT/TT: $p=0.359)$. After adjusting for cell type, residual disease, and chemotherapy regimen, patients with CT/TT genotypes vs. the CC genotype had an increased risk of disease progression $(\mathrm{HR}=1.40,95 \% \mathrm{CI}=1.00-1.95, p=0.049$, Table 2$)$, and a similar risk of death $(\mathrm{HR}=1.25,95 \% \mathrm{CI}=0.88-1.76, p=0.212$, Table 3$)$. When the seven women with a known BRCA1 mutation were removed from the analysis, the association between the BRCA1 P871L polymorphism and PFS $(\mathrm{HR}=1.36,95 \% \mathrm{CI}=0.97-1.91$, $p=0.073$ ) was no longer statistically significant (Table 3). Subgroup analyses stratified by histology (HGS vs. non-HGS), disease residual (microscopic vs. gross) or treatment arm (IV vs. IP) illustrated trends suggestive of a modest elevation in risk of disease progression for women with the CT/TT vs. CC genotype in these subgroups, but these associations were not statistically significant (Figure 2).

\section{BRCA2 N372H POLYMORPHISM ( $N=\mathbf{2 2 8}$ )}

All six AA women exhibited the CC genotype in BRCA2 N372H (Table 2) but the relationship between the $\mathrm{N} 372 \mathrm{H}$ polymorphism and race did not reach statistical significance in this study. Among the non-AA patients, the genotype for this polymorphism was distributed as $50 \%$ for AA, $44 \%$ for AC, and $6 \%$ for CC ( $p=0.381$ for 
Table 1 | Clinical Characteristics $(N=232)$.

\begin{tabular}{|c|c|}
\hline & No. (\%) \\
\hline \multicolumn{2}{|l|}{ Age (years) } \\
\hline$<55$ & $104(44.8)$ \\
\hline $55-64$ & $63(27.2)$ \\
\hline$\geq 65$ & $65(28.0)$ \\
\hline Median (range) & $57(32-83)$ \\
\hline \multicolumn{2}{|l|}{ Race } \\
\hline White & $213(91.8)$ \\
\hline Black & $7(3.0)$ \\
\hline Other & $12(5.2)$ \\
\hline \multicolumn{2}{|c|}{ GOG performance status } \\
\hline 0 & $101(43.5)$ \\
\hline 1 & 115 (49.6) \\
\hline 2 & $16(6.9)$ \\
\hline \multicolumn{2}{|l|}{ Cell type } \\
\hline Serous & $178(76.7)$ \\
\hline Endometrioid & $15(6.5)$ \\
\hline Clear cell (CC) & $14(6.0)$ \\
\hline Mutinous (MU) & $1(0.4)$ \\
\hline Other ${ }^{1}$ & $24(10.3)$ \\
\hline \multicolumn{2}{|l|}{ Tumor grade } \\
\hline 1 & $23(9.9)$ \\
\hline 2 & $92(39.7)$ \\
\hline 3 or clear cell & $117(50.4)$ \\
\hline \multicolumn{2}{|l|}{ Histology } \\
\hline $\mathrm{HGS}^{2}$ & $157(67.7)$ \\
\hline Non-HGS & 75 (32.3) \\
\hline \multicolumn{2}{|l|}{ Residual disease } \\
\hline Microscopic & $97(41.8)$ \\
\hline Gross & $135(58.2)$ \\
\hline \multicolumn{2}{|l|}{ Treatment ${ }^{3}$} \\
\hline $\mathrm{IP}$ Cis $+\mathrm{P}$ & $105(45.3)$ \\
\hline IV Cis $+P$ & $127(54.7)$ \\
\hline
\end{tabular}

HWE) (Table 2). There was no evidence that the BRCA2 N372H polymorphism was associated with PFS or OS (Figure 3; Table 2).

\section{DISCUSSION}

Both preclinical and clinical data suggest that alterations in BRCA1 or BRCA2 have prognostic value in ovarian cancer. Patients with germline mutations have improved clinical outcomes following the platinum chemotherapy $(9-11,31,37)$. Increased sensitivity to DNA-damaging anti-cancer drugs has been associated with BRCA1 or BRCA2 functional loss involving germline mutations or epigenetic changes. To extend these prior studies, we evaluated the prognostic value of the two common polymorphisms in BRCA1 and BRCA2 in GOG\#172. Common polymorphisms in BRCA1 P871L and BRCA2 N372H polymorphism were not strongly associated with clinical outcome (PFS or OS) in patients treated with $\mathrm{C}+\mathrm{P}$. Patients with the $\mathrm{CT}$ or TT vs. the CC genotype in BRCA1 P871L had a modest increased risk of disease recurrence attributable at least in part to the subset of GOG\#172 patients with a known germline mutation in BRCA1.

Several factors prompted our interest in the BRCA1 P871L and the BRCA2 N372H polymorphisms. First, both of these polymorphisms are very common and if one of them was found to be strongly associated with PFS or OS that biomarker would be able to be reliably detected in a minimally invasive blood sample. Second, relatively little is known about the biological, functional, and clinical impact of these polymorphisms. For example, the functional consequence of $\mathrm{C} \rightarrow \mathrm{T}$ transition in P871L in BRCA1 is not well understood. It is hypothesized that a $\mathrm{C} \rightarrow \mathrm{T}$ transition in this polymorphism alters the expression and/or function of BRCA1 enhancing chemosensitivity and outcome similar to that reported for ERCC1 (29, 34-36). The functional effects of BRCA1 P871L have been evaluated in breast cancer cell lines, and the different genotypes had distinctly different levels of BRCA1 protein (39). Based on this finding we expected enhanced sensitivity to platinum in women with the BRCA1 polymorphism. Several studies examined the association between BRCA1 P871L polymorphism and risk of developing ovarian. While there were reports that the P871L polymorphisms was associated with an increased risk of developing ovarian cancer $(23,24)$, this correlation was not confirmed based on large-scale studies $(25,26)$. In contrast, a recent study reported that this polymorphism (P871L) was associated with a reduced risk of developing cervical cancer (32). Among advanced gastric cancer patients treated with $\mathrm{C}+\mathrm{P}$, the P871L polymorphism was associated with improved PFS and OS (33).

Third, BRCA1 may have different roles in modulation of responses to DNA-damaging drugs compared with antimicrotubule drugs. It is proposed that BRCA1 mediates resistance to platinum agents involving activation of NER, HR, and FA/BRCA repair pathways and sensitivity to taxane-based chemotherapy involving mitotic spindle arrest followed by JNK/SAPK mediated apoptosis $(16,31,37)$. Thus far most clinical studies have focused on BRCA1 deficiency as a potential biomarker of response to platinum chemotherapy but not as a marker of taxane resistance. The potential contradictory effects of BRCA1 on the two most common agents used to treat advanced ovarian cancer make it difficult to appreciate how alterations in BRCA1 mediate tumor response in patients treated with a combination of $\mathrm{C}+\mathrm{P}$.

Recent studies on BRCA1/BRCA2 have concluded that a germline mutation in BRCA1 or BRCA2 was associated with improved survival in ovarian cancer patients and BRCA2 carriers had the best prognosis (40-42). Some investigators have proposed that BRCA1 and BRCA2 work at different stage in DNA damage response and in DNA repair. BRCA1 is functional in both checkpoint activation and DNA repair, whereas BRCA2 is a mediator of the core mechanism of homologous recombination (HR) (43). In the present study, we evaluated the N372H (rs144848) common variant of BRCA2 and determined that this polymorphism was not associated with PFS or OS. However, given the critical role that BRCA2 plays in HR, the effect that germline mutation in BRCA1 or BRCA2 has on increasing a woman's risk of breast and ovarian cancer and the fact that half the high-grade serous ovarian cancers have defects in HR $(27,44)$, other SNPs in BRCA1/BRCA2 may have clinical relevance. For example, extensive linkage disequilibrium (LD) exists across the BRCA1 gene with only two blocks of 
Table 2 | Associations between the BRCA1 P871L or BRCA2 N372H Polymorphism and Clinical Characteristics.

\begin{tabular}{|c|c|c|c|c|c|c|c|c|}
\hline & \multicolumn{4}{|c|}{ BRCA1 P871L } & \multicolumn{4}{|c|}{ BRCA2 N372H ${ }^{1}$} \\
\hline & CC & CT & $\mathbf{T T}$ & & AA & AC & CC & \\
\hline & No. (\%) & No. $(\%)$ & No. $(\%)$ & $p$-Value & No. (\%) & No. (\%) & No. $(\%)$ & $p$-Value \\
\hline Age in years (median) & 56.9 & 56.4 & 55.3 & $0.369^{a}$ & 54.9 & 57.9 & 55.6 & $0.820^{a}$ \\
\hline \multicolumn{9}{|l|}{ Race } \\
\hline White & $81(38.0)$ & $104(48.8)$ & $28(13.2)$ & $<0.001^{\mathrm{c}}$ & $106(50.5)$ & $91(43.3)$ & $13(6.2)$ & $0.155^{c}$ \\
\hline Black & $0(0)$ & $0(0)$ & $7(100)$ & & $6(100)$ & $0(0)$ & $0(0)$ & \\
\hline Other & $4(33.3)$ & 7 (58.3) & $1(8.3)$ & & $5(41.7)$ & $6(50.0)$ & $1(8.3)$ & \\
\hline \multicolumn{9}{|l|}{ Performance status } \\
\hline 0 & $34(33.7)$ & $53(52.5)$ & $14(13.9)$ & $0.461^{b}$ & $51(51.0)$ & $44(44.0)$ & $5(5.0)$ & $0.791^{b}$ \\
\hline 1 or 2 & $51(38.9)$ & $58(44.3)$ & $22(16.8)$ & & $66(51.6)$ & $53(41.4)$ & $9(7.0)$ & \\
\hline \multicolumn{9}{|l|}{ Histology } \\
\hline $\mathrm{HGS}^{2}$ & $55(35.0)$ & $76(48.4)$ & $26(16.6)$ & $0.700^{b}$ & 79 (51.3) & 66 (42.9) & $9(5.8)$ & $0.961^{b}$ \\
\hline Non-HGS & $30(40.0)$ & $35(46.7)$ & $10(13.3)$ & & $38(51.4)$ & 31 (41.9) & $5(6.8)$ & \\
\hline \multicolumn{9}{|l|}{ Tumor residual } \\
\hline No gross & $35(36.1)$ & $46(47.4)$ & $16(16.5)$ & $0.940^{b}$ & $48(50.0)$ & $42(43.8)$ & $6(6.3)$ & $0.944^{b}$ \\
\hline Gross & $50(37.0)$ & $65(48.2)$ & $20(14.8)$ & & $69(52.3)$ & $55(41.7)$ & $8(6.1)$ & \\
\hline \multicolumn{9}{|l|}{ Treatment $^{3}$} \\
\hline IP $C+P$ & $37(35.2)$ & $51(48.6)$ & $17(16.2)$ & $0.914^{b}$ & $52(50.0)$ & $46(44.2)$ & $6(5.8)$ & $0.889^{b}$ \\
\hline IV C + P & 48 (37.8) & $60(47.2)$ & $19(15.0)$ & & $65(52.4)$ & $51(41.1)$ & $8(6.5)$ & \\
\hline
\end{tabular}

${ }^{1}$ Genotype in BRCA2 N372H not determined for four specimens; CC, clear cell; $M U$, mucinous.

${ }^{2}$ HGS, high-grade (grade 2 or grade 3) serous tumor.

${ }^{3}$ IP, intraperitoneal; IV, intravenous; $C$, cisplatin; P, paclitaxel.

Wilcoxon rank-sum test.

${ }^{b}$ Pearson- $x^{2}$ test.

${ }^{c}$ Fisher exact test.

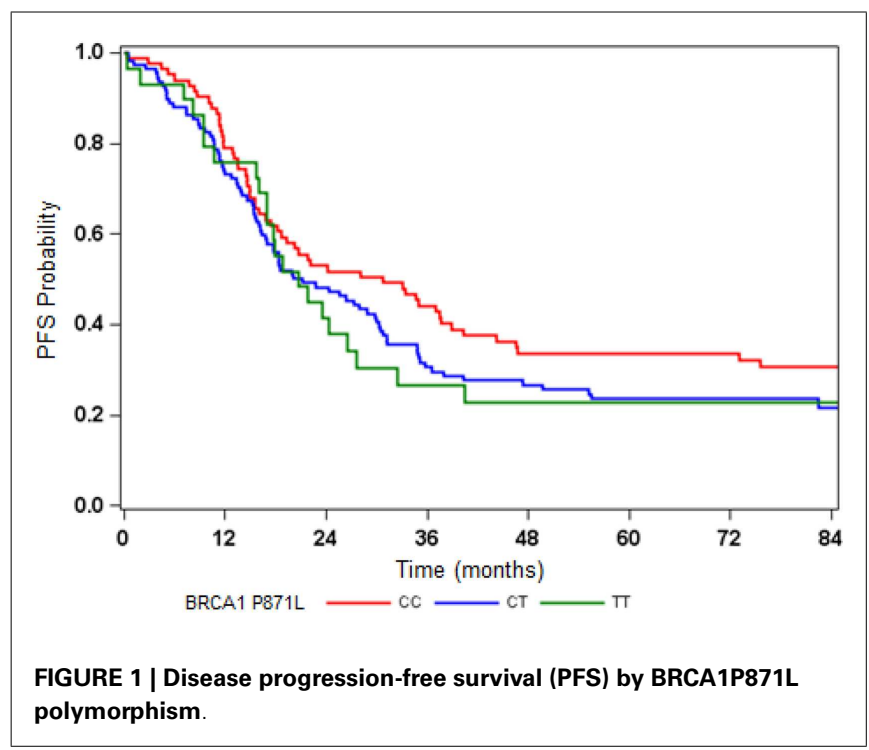

common genetic variations. The P871L polymorphism provided information regarding one LD block in the BRCA1 gene. Evaluation of a polymorphism in the other LD block in BRCA1 (e.g., Q356R) would be an efficient strategy for accessing the potential impact of all of the polymorphisms in the second LD block in the BRCA1 gene on treatment efficacy and/or outcome.
The clinical value of genetic variants in terms of prognosis and drug response are often more subtle than prognostic clinical factors making them more challenging to evaluate in cancer patients (38). Broadly defined clinical groupings and heterogeneous treatment regimens can have a strong influence on outcomes and mask the effects of individual genetic variants. One of the strengths of this study is that the population is relatively homogeneous. All of the women had optimally debulked stage III EOC and were uniformly managed as a result of their participation in a GOG phase III treatment protocol. Evaluation of other common polymorphisms in DNA repair remains a viable area of research given the role that DNA repair plays in drug sensitivity and resistance as well as genomic chaos and poor outcome in solid tumors like EOC (44) with high initial response rates to platinum and taxane-based chemotherapy and poor long term survival with 10 -year survival rates approaching $10 \%$.

In summary, common polymorphisms in BRCA1 (P871L) and BRCA2 $(\mathrm{N} 372 \mathrm{H})$ were not associated with PFS or OS in women with optimally resected, stage III EOC treated with $\mathrm{C}+\mathrm{P}$. This study provides supportive evidence that germline mutations in BRCA1 enhance sensitivity and PFS.

\section{ACKNOWLEDGMENTS}

The authors are indebted to Drs. Mark Brady and Andrew Berchuck as well as the GOG Publications Subcommittee for critical review of the manuscript and providing helpful suggestions, and to Anne Reardon for assistance in preparing this 
Table 3 | Progression-free survival (PFS) and overall survival (OS) by BRCA1 P871L and BRCA2 N372H polymorphisms for patients treated with cisplatin/paclitaxel-based chemotherapy.*

\begin{tabular}{|c|c|c|c|c|c|c|c|}
\hline & \multirow[t]{2}{*}{ No. $(\%)$} & \multicolumn{3}{|c|}{ PFS } & \multicolumn{3}{|c|}{ os } \\
\hline & & HR & $95 \% \mathrm{Cl}$ & $p$-Value & HR & $95 \% \mathrm{Cl}$ & $p$-Value \\
\hline \multicolumn{8}{|c|}{ All patients } \\
\hline $\mathrm{CC}$ & $85(37.8)$ & Referent & & & Referent & & \\
\hline CT & $111(49.3)$ & 1.37 & $0.96-1.94$ & 0.079 & 1.21 & $0.84-1.74$ & 0.300 \\
\hline $\mathrm{CC}+\mathrm{TT}$ & & 1.40 & $1.00-1.95$ & 0.049 & 1.25 & $0.88-1.76$ & 0.212 \\
\hline \multicolumn{8}{|c|}{ By excluding seven cases with known brca1 mutations } \\
\hline $\mathrm{CC}$ & $83(38.1)$ & Reference & & & Reference & & \\
\hline $\mathrm{CT}$ & $108(49.5)$ & 1.32 & $0.93-1.88$ & 0.123 & 1.21 & $0.84-1.76$ & 0.304 \\
\hline TT & 27 (12.4) & 1.54 & $0.93-2.55$ & 0.092 & 1.31 & $0.76-2.26$ & 0.327 \\
\hline $\mathrm{CC}+\mathrm{TT}$ & & 1.36 & $0.97-1.91$ & 0.073 & 1.23 & $0.87-1.76$ & 0.244 \\
\hline $\mathrm{CC}$ & $14(6.1)$ & 0.81 & $0.42-1.57$ & 0.533 & 0.76 & $0.36-1.59$ & 0.462 \\
\hline$A C+C C$ & & 1.03 & $0.75-1.42$ & 0.844 & 1.13 & $0.80-1.58$ & 0.492 \\
\hline
\end{tabular}

Hazard ratio (HR) and 95\% confidence interval (CI) estimated from Cox regression model adjusted for cell type, tumor residual, and type of treatment.

*Analysis limited to patients by excluding African American women.

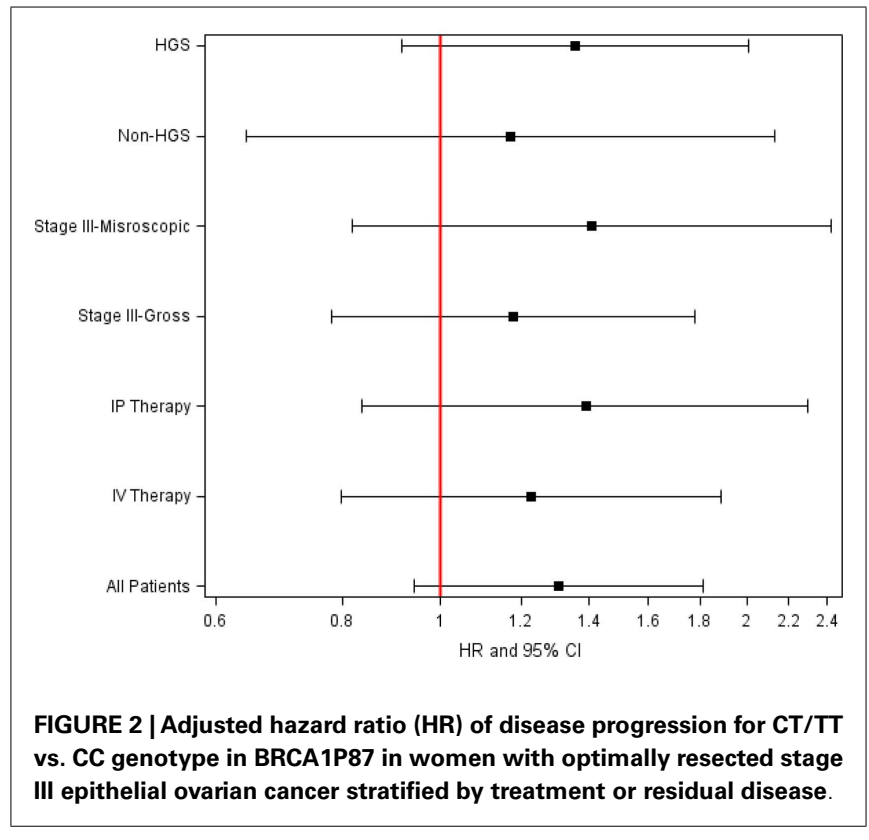

manuscript for publication. This study was supported by National Cancer Institute grants to the GOG Administrative Office and the GOG Tissue Bank (CA 27469), the GOG Statistical and Data Center (CA 37517), and to Roswell Park Cancer Institute (CA 016056-01), grants from the GOG/Ovarian Cancer Research Fund New Investigator Award (Thomas C. Krivak), The Jennie K. Scaife Foundation (Julie A. DeLoia), The Pittsburgh Foundation (Julie A. DeLoia), and the Department of Defense (W81XWH-10-2-0018

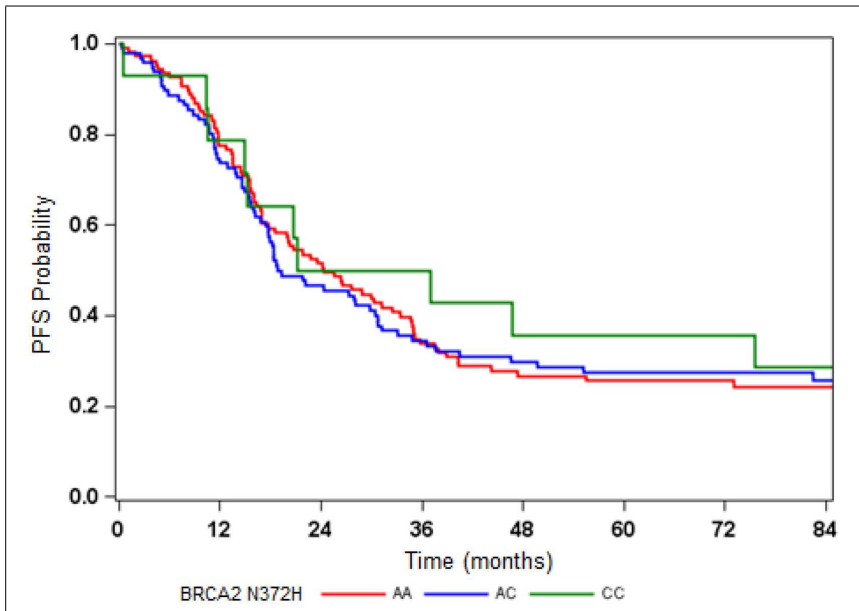

FIGURE 3 | Disease progression-free survival (PFS) by BRCA2 N372H polymorphism.

and W81XWH-11-2-0131). The following GOG member institutions participated in this translational research study: University of Alabama at Birmingham, Duke University Medical Center, Abington Memorial Hospital, University of Rochester Medical Center, Walter Reed Army Medical Center, Wayne State University, University of Minnesota Medical School, Emory University Clinic, University of Mississippi Medical Center, Colorado GOG, P.C., University of California at Los Angeles, University of Washington, University of Pennsylvania Cancer Center, Milton S. Hershey Medical Center, Georgetown University Hospital, University of 
Cincinnati, University of North Carolina School of Medicine, University of Iowa Hospitals and Clinics, University of Texas Southwestern Medical Center at Dallas, Indiana University Medical Center, Wake Forest University School of Medicine, Albany Medical College, University of California Medical Center at Irvine, Tufts-New England Medical Center, Rush-Presbyterian-St. Luke's Medical Center, SUNY Downstate Medical Center, University of Kentucky, Community Clinical Oncology Program, The Cleveland Clinic Foundation, Johns Hopkins Oncology Center, SUNY at

\section{REFERENCES}

1. Cannistra SA. Cancer of the ovary. $N$ Engl J Med (2005) 351:2519-29. doi:10.1056/NEJMra041842

2. Ozols RF. Gynecologic Oncology Group (GOG-USA) trials in ovarian cancer. Adv Exp Med Biol (2008) 622:131-43. doi:10.1007/ 978-0-387-68969-2_11

3. Marksman M. Pharmaceutical management of ovarian cancer: current status. Drugs (2008) 68:771-89. doi:10.2165/00003495200868060-00004

4. McGuire WP, Hoskins WJ, Brady MF, Kucera PR, Partridge EE, Look $\mathrm{KY}$, et al. Cyclophosphamide and cisplatin compared with paclitaxel and cisplatin in patients with stage III and stage IV ovarian cancer. $N$ Engl J Med (1996) 334:1-6. doi:10. 1056/NEJM199601043340101

5. Agarwal R, Kaye SB. Ovarian cancer: strategies for overcoming resistance to chemotherapy. Nat Rev Cancer (2003) 3:502-16. doi:10.1038/ nrc1123

6. King MC, Marks JH, Mandell JB. Breast and ovarian cancer risks due to inherited mutations in BRCA1 and BRCA2. Science (2003) 302:643-6. doi:10.1126/ science. 1088759

7. Rubin SC, Benjamin I, Behbakht K, Takahashi H, Morgan MA, LiVolsi $\mathrm{VA}$, et al. Clinical and pathological features of ovarian cancer in women with germ-line mutations of BRCA1. N Engl J Med (1996) 335:1413-6. doi:10.1056/ NEJM199611073351901

8. Boyd J, Sonoda Y, Federici MG, Bogomolniy F, Rhei E, Maresco DL, et al. Clinicopathologic features of BRCA-linked and sporadic ovarian cancer. JAMA (2000) 283:2260-5. doi:10.1001/jama.283.17.2260

9. Ben David Y, Chetrit A, HirshYechezkel G, Friedman E, Beck BD, Beller U, et al. Effect of BRCA mutations on the length of survival in epithelial ovarian tumors. $J$ Clin Oncol (2002) 20:463-6. doi:10. 1200/JCO.20.2.463

10. Cass I, Baldwin RL, Varkey T, Moslehi R, Narod SA, Karlan
BY. Improved survival in women with BRCA-associated ovarian carcinoma. Cancer (2003) 97:2187-95. doi:10.1002/cncr.11310

11. Chetrit A, Hirsh-Yechezkel G, Ben David Y, Lubin F, Friedman E, Sadetzki S. Effect of BRCA1/2 mutations on long-term survival of patients with invasive ovarian cancer: the national Israeli study of ovarian cancer. J Clin Oncol (2008) 26:20-5. doi:10.1200/JCO.2007.11. 6905

12. Husain A, He G, Venkatraman ES, Spriggs DR. BRCA1 upregulation is associated with repair-mediated resistance to cisdiamminedichloroplatinum(II). Cancer Res (1998) 58:1120-3.

13. Kennedy RD, Quinn JE, Mullan PB, Johnston PG, Harkin DP. The role of BRCA1 in the cellular response to chemotherapy. J Natl Cancer Inst (2004) 96:1659-68. doi: 10.1093/jnci/djh312

14. Nusbaum R, Isaacs C. Management updates for women with a BRCA1 or BRCA2 mutation. $\mathrm{Mol}$ Diagn Ther (2007) 11:133-44. doi: 10.1007/BF03256234

15. Weberpals JI, Clark-Knowles KV, Vanderhyden BC. Sporadic epithelial ovarian cancer: clinical relevance of BRCAl inhibition in the DNA damage and repair pathway. J Clin Oncol (2008) 26:3259-67. doi:10. 1200/JCO.2007.11.3902

16. Quinn JE, James CR, Stewart GE, Mulligan JM, White P, Chang GK, et al. BRCA1 mRNA expression levels predict for overall survival in ovarian cancer after chemotherapy. Clin Cancer Res (2007) 13:7413-20. doi:10.1158/10780432.CCR-07- 1083

17. Thrall M, Gallion HH, Kryscio R, Kapali M, Armstrong DK, DeLoia JA. BRCA1 expression in a large series of sporadic ovarian carcinomas: a Gynecologic Oncology Group study. Int J Gynecol Cancer (2006) 16(Suppl 1):166-71. doi:10. 1111/j.1525-1438.2006.00504.x

18. Weberpals J, Garbuio K, O’Brien A, Clark-Knowles K, Doucette S, Antoniouk $\mathrm{O}$, et al. The DNA repair

Stony Brook, Eastern Pennsylvania GYN/ONC Center, PC, Washington University School of Medicine, Cooper Hospital/University Medical Center, Columbus Cancer Council, University of Massachusetts Medical Center, Fox Chase Cancer Center, Medical University of South Carolina, Women's Cancer Center, University of Oklahoma, University of Virginia, University of Chicago, Tacoma General Hospital, Thomas Jefferson University Hospital, Case Western Reserve University, Tampa Bay Cancer Consortium, North Shore University Hospital, Brookview Research, Inc.

proteins BRCA1 and ERCC1 as predictive markers in sporadic ovarian cancer. Int J Cancer (2009) 124:806-15. doi:10.1002/ijc.23987

19. Wachters FM, Wong LS, Timens W, Kampinga HH, Groen HJ. ERCC1, hRad51, and BRCA1 protein expression in relation to tumour response and survival of stage III/IV NSCLC patients treated with chemotherapy. Lung Cancer (2005) 50:211-9. doi:10.1016/j.lungcan. 2005.06.013

20. Taron M, Rosell R, Felip E, Mendez P, Souglakos J, Ronco MS, et al. BRCA1 mRNA expression levels as an indicator of chemoresistance in lung cancer. Hum Mol Genet (2004) 13:2443-9. doi:10. 1093/hmg/ddh260

21. Grabsch H, Dattani M, Barker L, Maughan N, Maude K, Hansen O, et al. Expression of DNA doublestrand break repair proteins ATM and BRCA1 predicts survival in colorectal cancer. Clin Cancer Res (2006) 12:1494-500. doi:10.1158/ 1078-0432.CCR-05-2105

22. Packer BR, Yeager M, Burdett L, Welch R, Beerman M, Qi L, et al. SNP500Cancer: a public resource for sequence validation, assay development, and frequency analysis for genetic variation in candidate genes. Nucleic Acids Res (2006) 34:D61721. doi:10.1093/nar/gkj151 (Database issue)

23. Durocher F, Shattuck-Eidens D, McClure M, Labrie F, Skolnick $\mathrm{MH}$, Goldgar DE, et al. Comparison of BRCA1 polymorphisms, rare sequence variants and/or missense mutations in unaffected and breast/ovarian cancer populations. Hum Mol Genet (1996) 5:835-42. doi:10.1093/hmg/5.6.835

24. Janezic SA, Ziogas A, Krumroy LM, Krasner M, Plummer SJ, Cohen P, et al. Germline BRCA1 alterations in a population-based series of ovarian cancer cases. Hum Mol Genet (1999) 8:889-97. doi:10.1093/hmg/ 8.5.889

25. Wenham RM, Schildkraut JM, McLean K, Calingaert B, Bentley RC, Marks J, et al. Polymorphisms in BRCA1 and BRCA2 and risk of epithelial ovarian cancer. Clin Cancer Res (2003) 9:4396-403.

26. Auranen A, Song H, Waterfall C, Dicioccio RA, Kuschel B, Kjaer SK, et al. Polymorphisms in DNA repair genes and epithelial ovarian cancer risk. Int J Cancer (2005) 17:611-8. doi:10.1002/ijc.21047

27. Auranen A, Spurdle AB, Chen $\mathrm{X}$, Lipscombe J, Purdie DM, Hopper JL, et al. BRCA2 Arg372Hispolymorphism and epithelial ovarian cancer risk. Int J Cancer (2003) 103:427-30. doi:10.1002/ijc.10814

28. Armstrong DK, Bundy B, Wenzel L, Huang HQ, Baergen R, Lele S, et al. Intraperitoneal cisplatin and paclitaxel in ovarian cancer. $N$ Engl J Med (2006) 354:34-43. doi:10. 1056/NEJMoa052985

29. Krivak TC, Darcy KM, Tian C, Armstrong D, Baysal BE, Gallion $\mathrm{H}$, et al. Relationship between ERCC1 polymorphisms, disease progression and survival in the Gynecologic Oncology Group phase III trial of intraperitoneal versus intravenous cisplatin and paclitaxel for stage III epithelial ovarian cancer. J Clin Oncol (2008) 26:3598-606. doi:10.1200/JCO. 2008.16.1323

30. Winter WE III, Maxwell GL, Tian C, Tian C, Carlson JW, Ozols RF, et al. Prognostic factors for stage III epithelial ovarian cancer: a Gynecologic Oncology Group study. J Clin Oncol (2007) 25:3621-7. doi: 10.1200/JCO.2006.10.2517

31. Tagliaferri P, Ventura M, Baudi F, Cucinotto I, Arbitrio M, Di Martino MT, et al. RCA1/2 genetic background-based therapeutic tailoring of human ovarian cancer: hope or reality? J Ovarian Res (2009) 2:14. doi:10.1186/1757-2215-2-14

32. Zhou X, Han S, Wang S, Chen $X$, Dong J, Shi X, et al. Polymorphisms in HPV E6/E7 protein interacted genes and risk of cervical cancer in Chinese women: a case-control analysis. Gynecol Oncol (2009) 114:327-31. doi:10.1016/j. ygyno.2009.05.011 
33. Shim HJ, Yun JY, Hwang JE, Bae WK, Cho SH, Lee JH, et al. BRCA1 and XRCC1 polymorphisms associated with survival in advanced gastric cancer treated with taxane and cisplatin. Cancer Sci (2010) 101:1247-54. doi:10.1111/j.13497006.2010.01514.x

34. Smith S, Su D, Rigault de la Longrais IA, et al. ERCC1 genotype and phenotype in epithelial ovarian cancer identify patients likely to benefit from paclitaxel treatment in addition to platinumbased therapy. J Clin Oncol (2007) 25:5172-9. doi:10.1200/JCO.2007. 11.8547

35. Steffensen KD, Waldstrøm M, Jeppesen U, Brandslund I, Jakobsen A. Prediction of response to chemotherapy by ERCC1 immunohistochemistry and ERCC1 polymorphism in ovarian cancer. Int J Gynecol Cancer (2008) 18:702-10. doi:10.1111/j.1525-1438.2007. 01068.x

36. Kim HS, Kim MK, Chung $\mathrm{HH}$, Kim JW, Park NH, Song YS, et al. Genetic polymorphisms affecting clinical outcomes in epithelial ovarian cancer patients treated with taxanes and platinum compounds: a Korean population-based study. Gynecol Oncol (2009) 113:264-9. doi:10.1016/j.ygyno.2009.01.002

37. Quinn JE, Carser JE, James CR, Kennedy RD, Harkin DP. BRCA1 and implications for response to chemotherapy in ovarian cancer. Gynecol Oncol (2009) 113:134-42. doi:10.1016/j.ygyno.2008.12.015

38. Robert J, Morvan VL, Smith D, Pourquier P, Bonnet J. Predicting drug response and toxicity based on gene polymorphisms. Crit Rev Oncol Hematol (2005) 54:171-96. doi:10.1016/ j.critrevonc.2005.01.005

39. Nicoloso MS, Sun H, Spizzo $\mathrm{R}$, Kim H, Wickramasinghe $\mathrm{P}$, Shimizu M, et al. Single-nucleotide polymorphisms inside microRNA target sites influence tumor susceptibility. Cancer Res (2010) 70:2789-98. doi:10.1158/00085472.CAN-09-3541

40. Yang D, Khan S, Sun Y, Hess K, Shmulevich I, Sood AK, et al. Association of BRCAl and BRCA2 mutations with survival, chemotherapy sensitivity, and gene mutator phenotype in patients with ovarian cancer. JAMA (2011) 306:1557-65. doi:10.1001/jama.2011.1456
41. Bolton KL, Chenevix-Trench G, Goh C. Association between BRCA1 and BRCA2 mutations and survival in women with invasive epithelial ovarian cancer. JAMA (2012) 307(4):382-90. doi:10.1001/ jama. 2012.20

42. Hyman DM, Zhou Q, Iasonos A, Grisham RN, Arnold AG Phillips MF. Improved survival for BRCA2-associated serous ovarian cancer compared with both BRCA-negative and BRCA1associated serous ovarian cancer. Cancer (2012) 118(15):3703-9. doi:10.1002/cncr.26655

43. Roy R, Chun J, Powell SN. BRCA1 and BRCA2: different roles in a common pathway of genome protection. Nat Rev Cancer (2011) 12:68-78. doi:10.1038/nrc3181

44. Cancer Genome Atlas Research Network, Bell D, Berchuck A, Birrer M, Chien J, Cramer D. Integrated genomic analyses of ovarian carcinoma. Nature (2011) 474(7353):609-15 doi:10.1038/nature10166

Conflict of Interest Statement: The authors declare that the research was conducted in the absence of any commercial or financial relationships that could be construed as a potential conflict of interest.

Received: 28 May 2013; paper pending published: 28 June 2013; accepted: 29 July 2013; published online: 12 August 2013. Citation: Tian CQ, Darcy KM, Krivak TC, DeLoia JA, Armstrong D, Davis $W$, Zhao H, Moysich $K$ and Ambrosone CB (2013) Assessment of the prognostic value of two common variants of BRCA1 and BRCA2 genes in ovarian cancer patients treated with cisplatin and paclitaxel: a Gynecologic Oncology Group study. Front. Oncol. 3:206. doi: 10.3389/fonc.2013.00206

This article was submitted to Frontiers in Women's Cancer, a specialty of Frontier in Oncology.

Copyright (c) 2013 Tian, Darcy, Krivak, DeLoia, Armstrong, Davis, Zhao, Moysich and Ambrosone. This is an openaccess article distributed under the term of the Creative Commons Attribution License (CC BY). The use, distribution or reproduction in other forums is permitted, provided the original author(s) or licensor are credited and that the original publication in this journal is cited, in accordance with accepted academic practice. No use, distribution or reproduction is permitted which does not comply with these terms. 